\title{
OPTIMASI EFISIENSI KOLOM DALAM KROMATOGRAFI MENGGUNAKAN VISUAL BASIC 2008
}

\author{
Harry S.J. Koleangan ${ }^{1)}$ \\ 1) Program Studi Kimia FMIPA Universitas Sam Ratulangi \\ Jl. Kampus Unsrat, Manado 95115 \\ e-mail: koleanganharry@yahoo.com
}

\begin{abstract}
ABSTRAK
Telah dibuat sebuah program aplikasi yang ditujukan untuk optimasi efisiensi kolom yang digunakan dalam pemisahan secara kromatografi. Parameter-parameter untuk optimasi ini dianalisis menggunakan metode eliminasi Gauss dalam bentuk program komputer yang ditulis menggunakan bahasa pemrograman Visual Basic 2008 Express Edition. Penggunaan program ini terhadap suatu data sekunder memberikan hasil efisiensi kolom optimum, yang dinyatakan sebagai tinggi plat teoritis $(\mathrm{H})$ terkecil, sebesar $0,0223 \mathrm{~cm}$ yang dicapai pada laju alir optimum $20,6 \mathrm{~cm} /$ det.
\end{abstract}

Kata kunci: Efisiensi kolom, eliminasi Gauss, persamaan van Deemter, Visual Basic 2008

\section{OPTIMIZATION OF COLUMN EFFICIENY IN CHROMATOGRAPHY USING VISUAL BASIC 2008}

\begin{abstract}
An application program to optimize column efficiency in chromatographic separation had been developed. Optimization parameters were analyzed using Gauss elimination method which was written in the form of a computer program using Visual Basic 2008 Express Edition programming language. Application of the program on the secondary data gave the optimum column efficiency, which was represented as height equivalent to a theoritical plate $(\mathrm{H})$, of $0,0223 \mathrm{~cm}$ which was achieved at optimum flow rate of $20,6 \mathrm{~cm} / \mathrm{det}$
\end{abstract}

Keywords: Column efficiency, Gauss elimination, van Deemter equation, Visual Basic 2008

\section{PENDAHULUAN}

Efisiensi kolom merupakan elemen penting dalam melakukan pemisahan secara kromatografi karena keterpisahan komponenkomponen sampel dalam kromatografi sangat ditentukan oleh efisiensi kolom. Efisiensi kolom dinyatakan sebagai tinggi plat teoritis (Height Equivalent to a Theoritical Plate/HETP) dan diberi simbol $H$, di mana nilai $H$ yang kecil menunjukkan efisiensi kolom yang tinggi. Faktor-faktor yang mempengaruhi efisiensi kolom adalah difusi Eddy, difusi longitudinal, dan perbedaan kecepatan transfer massa yang terjadi di dalam kolom kromatografi selama proses pemisahan berlangsung. Pengaruh ketiga parameter ini terhadap tinggi plat teoritis dirumuskan dalam persamaan van Deemter, yaitu

$$
H=A+\frac{B}{\mu}+\mu C
$$

di mana $A$ adalah difusi Eddy, $B / \mu$ adalah difusi longitudinal, $\mu C$ adalah pengaruh transfer massa, dan $\mu$ adalah laju alir fasa gerak.

Dari persamaan ini terlihat bahwa difusi longitudinal berbanding terbalik dengan laju alir sedangkan pengaruh transfer massa berbanding lurus dengan laju alir, sehingga untuk mendapatkan efisiensi kolom tertinggi (yaitu, $H$ minimum) maka harus dicari laju alir optimum dan nilai $A, B$, dan $C$ harus diketahui. Laju alir optimum dapat diperoleh dengan cara mendiferensialkan persamaan (1) terhadap laju alir $(\mu)$ sehingga diperoleh

$\mu_{o p t}=\sqrt{\frac{B}{C}}$ 
Dari persamaan (2) nampak bahwa untuk menemukan laju alir optimum maka parameter $B$ dan $C$ harus diketahui, sedangkan untuk menentukan parameterparameter van Deemter ini dibutuhkan tiga persamaan linear simultan.

Penyelesaian persamaan linear simultan membutuhkan jumlah operasi aritmetika yang cukup banyak, berulang dan memerlukan ketelitian yang tinggi sehingga apabila dilakukan secara manual akan membutuhkan waktu yang cukup lama dan seringkali menjemukan. Dengan sebuah program komputer, maka penyelesaian tersebut dapat dilakukan dengan waktu yang sangat singkat dan dengan tingkat akurasi yang tinggi. Tujuan penelitian ini adalah membuat sebuah program komputer menggunakan bahasa pemrograman Visual Basic 6 yang dapat digunakan untuk mencari laju alir yang menghasilkan efisiensi kolom tertinggi.

\section{METODOLOGI PENELITIAN}

\section{Data dan Cara Perhitungan}

Data penelitian ini merupakan data sekunder yang diambil dari textbook Analytical Chemistry: Principles tulisan John H. Kennedy (1990), dengan rincian sebagai berikut: sebuah kolom kromatografi gas (GC) yang memiliki panjang $150 \mathrm{~cm}$ dan diisi dengan partikel-partikel berukuran $50 \square \mathrm{m}$ hendak dioptimumkan efisiensi kolomnya. Hasil eksperimental untuk elusi satu analit disajikan dalam tabel di bawah ini.

\begin{tabular}{|c|c|c|c|}
\hline Percobaan & $u(\mathrm{~cm} / \mathrm{s})$ & $\mathrm{t}_{\mathrm{R}}(\mathrm{s})$ & $W(\mathrm{~s})$ \\
\hline 1 & 10 & 450 & 24 \\
2 & 30 & 150 & 7,5 \\
3 & 50 & 90 & 5 \\
\hline
\end{tabular}

di mana : $t_{R}=$ waktu retensi

$$
W=\text { lebar pita }
$$

Dari data waktu retensi dan lebar pita, jumlah plat teoritis $(N)$ untuk masingmasing laju alir dihitung melalui persamaan berikut:

$$
N=\left(\frac{4 t_{R}}{W}\right)^{2}
$$

di mana hasil yang diperoleh selanjutnya digunakan untuk menentukan tinggi plat teoritis untuk setiap laju alir dengan menggunakan persamaan
$H=\frac{L}{N}$

di mana $L$ adalah panjang kolom yang digunakan. Dengan menggunakan data dari tiga percobaan di atas maka diperoleh tiga tinggi plat teoritis $(H)$ sehingga didapatkan persamaan linear simultan sebagai berikut:

$$
\begin{aligned}
& H_{1}=A+\frac{B}{10}+10 C \\
& H_{2}=A+\frac{B}{30}+30 C \\
& H_{3}=A+\frac{B}{50}+50 C
\end{aligned}
$$

Perhitungan selengkapnya untuk menentukan $N$ dan $H$ dilakukan melalui program komputer yang dibuat.

\section{Algoritma Program}

Ada tiga tahapan utama untuk menyelesaikan suatu persamaan linear simultan sebagaimana dalam persamaan van Deemter. Untuk mempermudah pemrograman, setiap tahapan ini dijadikan prosedur pemrograman tersendiri. Ketiga prosedur tersebut adalah: MasukkanData untuk memasukkan data, Eliminasi untuk melakukan eliminasi, dan SubstitusiBalik untuk melakukan substitusi balik.

Algoritma pemasukkan data adalah sebagai berikut:

Masukkan panjang kolom

For $\mathrm{i}=0$ to 2

Masukkan data laju alir ke-(i)

Masukkan data waktu retensi ke-(i)

Masukkan data lebar pita ke-(i)

Hitung jumlah plat teoritis ke-(i)

Hitung tinggi plat teoritis ke-(i)

Next i

Proses eliminasi dilakukan menggunakan metode Gauss. Untuk mempermudah penyajian algoritma untuk proses eliminasi, maka algoritmanya dituliskan dalam bentuk flowchart sebagai berikut: 


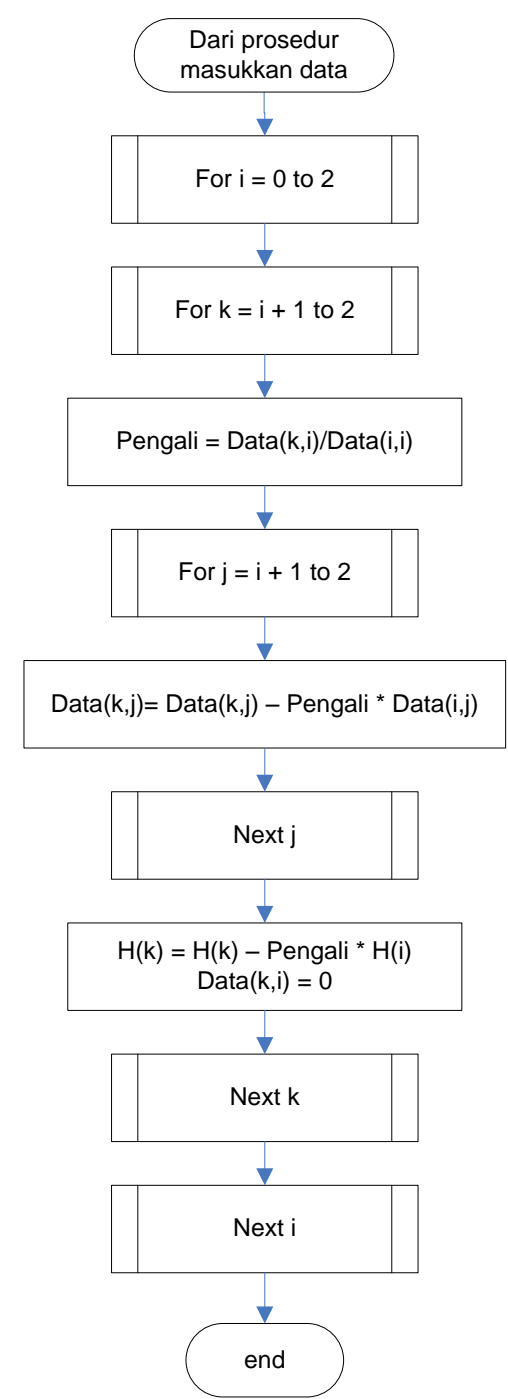

Gambar 1. Flowchart Proses Eliminasi Gauss

Selanjutnya, algoritma dari proses substitusi balik dalam bentuk flowchart terlihat pada gambar 2 .

\section{Kode Program}

Kode program selengkapnya dapat dilihat pada lampiran.

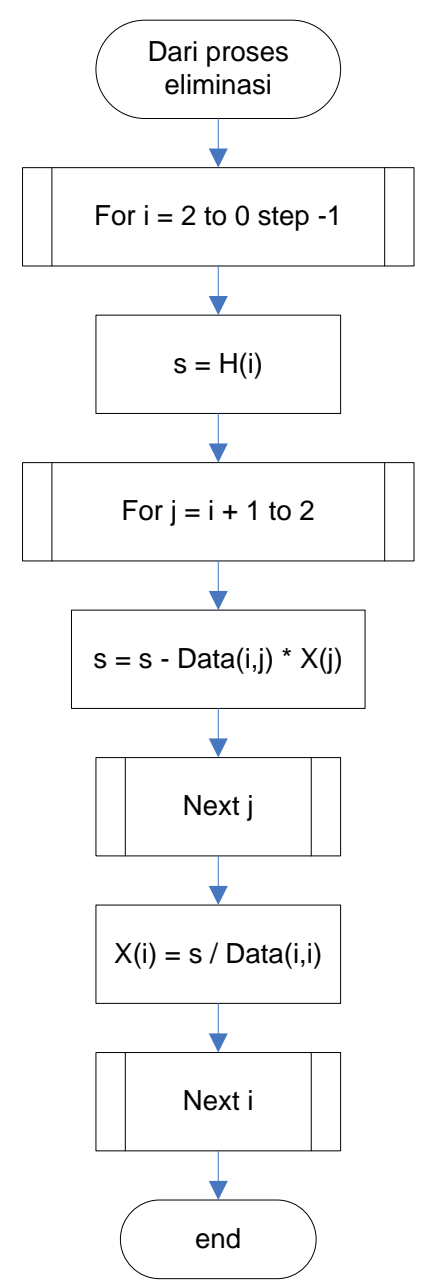

Gambar 2. Flowchart Proses Substitusi Balik

\section{HASIL DAN PEMBAHASAN}

Program yang telah dibuat diuji menggunakan data yang ada. Ketika pertama kali dijalankan, program meminta masukkan data. Dengan memasukkan data yang ada maka diperoleh tampilan sebagaimana disajikan dalam Gambar 3. 


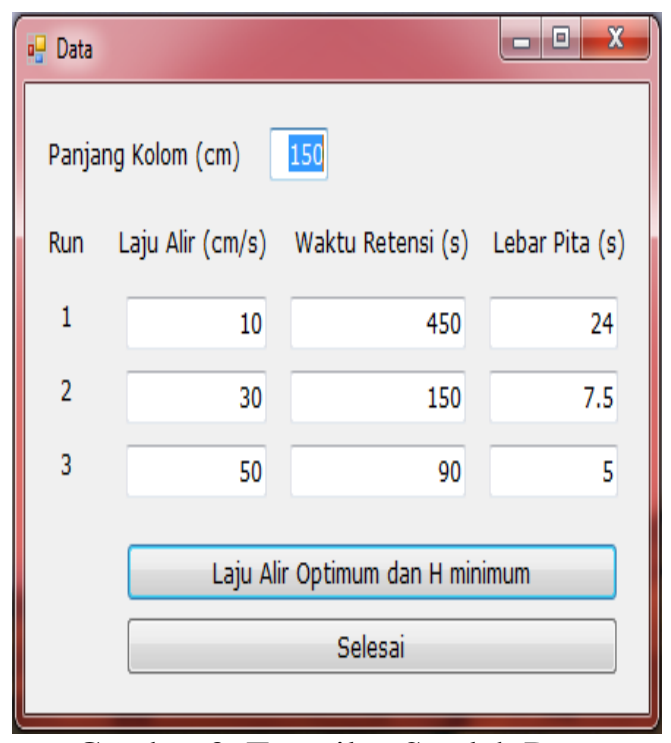

Gambar 3. Tampilan Setelah Data

Dimasukkan

Data yang telah dimasukkan selanjutnya diproses untuk menghasilkan laju alir optimum dan $H$ minimum. Hal ini dilakukan dengan menekan tombol Laju Optimum \& $H$ minimum sehingga diperoleh tampilan seperti dalam Gambar 4.

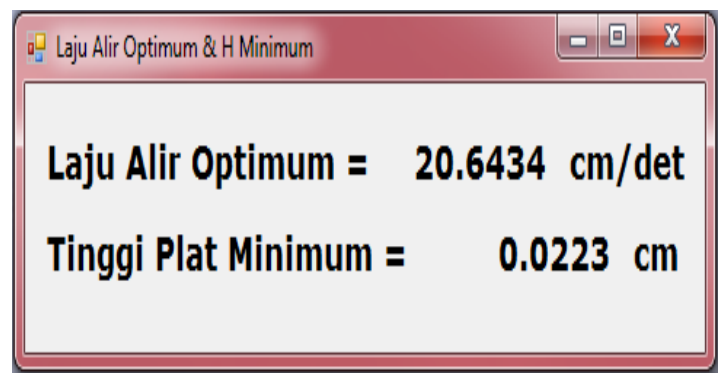

Gambar 4. Tampilan Setelah Tombol Laju Alir Optimum \& H Minimum Ditekan

Hasil perhitungan di atas diperoleh melalui tiga prosedur program. Prosedur pertama untuk memasukkan data dan menghitung $N$ dan $H$, dan dua prosedur lainnya berfungsi untuk menghitung $A, B$, dan $C$.

Kode program untuk prosedur yang bertugas untuk memasukkan data dan menghitung nilai $N$ dan $H$ adalah:

'subrutin untuk memasukkan data

Private Sub MasukkanData()

Panjang $=\mathrm{CDbl}($ txtPanjang.Text $)$

'ulangan pertama

$\operatorname{DataMentah}(0,0)=$

CDbl(txtLajuAlir1.Text)

$\operatorname{DataMentah}(0,1)=$

CDbl(txtWaktuRetensi1.Text)
$\operatorname{DataMentah}(0,2)=$

CDbl(txtLebarPita1.Text)

'ulangan kedua

$\operatorname{DataMentah}(1,0)=$

CDbl(txtLajuAlir2.Text)

$\operatorname{DataMentah}(1,1)=$

CDbl(txtWaktuRetensi2.Text)

$\operatorname{DataMentah}(1,2)=$

CDbl(txtLebarPita2.Text)

'ulangan ketiga

$\operatorname{DataMentah}(2,0)=$

CDbl(txtLajuAlir3.Text)

$\operatorname{DataMentah}(2,1)=$

CDbl(txtWaktuRetensi3.Text)

$\operatorname{DataMentah}(2,2)=$

CDbl(txtLebarPita3.Text)

End Sub

'subrutin untuk menghitung koefisien dari $\mathrm{A}, \mathrm{B}, \mathrm{C}$ dan nilai $\mathrm{N}$ dan $\mathrm{H}$ dalam pers VD

Private Sub KoefABC()

Dim i, j As Integer i=banyaknya

baris, $\mathrm{j}=$ banyaknya kolom

For $\mathrm{i}=0$ To 2

$\mathrm{N}(\mathrm{i})=(4 *$ DataMentah $(\mathrm{i}, 1) /$

DataMentah(i, 2) $)^{\wedge} 2$

$\mathrm{H}(\mathrm{i})=$ Panjang $/ \mathrm{N}(\mathrm{i})$

For $\mathrm{j}=0$ To 3

Select Case $\mathrm{j}$

Case 0

$\operatorname{Data}(\mathrm{i}, \mathrm{j})=1$

Case 1

$\operatorname{Data}(\mathrm{i}, \mathrm{j})=1 / \operatorname{DataMentah}(\mathrm{i}, 0)$

Case 2

$\operatorname{Data}(\mathrm{i}, \mathrm{j})=\operatorname{DataMentah}(\mathrm{i}, 0)$

Case 3

End Select

$\operatorname{Data}(\mathrm{i}, \mathrm{j})=\mathrm{H}(\mathrm{i})$

Next

Next

End Sub

Setelah data dimasukkan, maka proses selanjutnya adalah eliminasi. Kode program untuk melakukan hal ini adalah

'subrutin untuk melakukan eliminasi

Private Sub Eliminasi()

Dim i, j, k As Integer

Dim Pengali As Double

For $\mathrm{i}=0$ To 2

For $\mathrm{k}=\mathrm{i}+1$ To 2

Pengali $=\operatorname{Data}(\mathrm{k}, \mathrm{i}) / \operatorname{Data}(\mathrm{i}, \mathrm{i})$

For $\mathrm{j}=\mathrm{i}+1$ To 2

$\operatorname{Data}(k, j)=\operatorname{Data}(k, j)-$ Pengali $*$ Data $(i, j)$ 


\author{
Next \\ $\mathrm{H}(\mathrm{k})=\mathrm{H}(\mathrm{k})$ - Pengali * $\mathrm{H}(\mathrm{i})$ \\ $\operatorname{Data}(\mathrm{k}, \mathrm{i})=0$ \\ Next \\ Next \\ End Sub
}

Kode program ini akan melakukan perhitungan dalam beberapa tahap. Pertama, program akan mengeliminasi $A$ dalam persamaan 5 sampai 7 , sehingga dihasilkan dua persamaan yang hanya mengandung $B$ dan $C$. Selanjutnya program akan mengeliminasi $B$, sehingga dihasilkan satu persamaan yang mengandung $C$.

Setelah diperoleh satu persamaan yang mengandung satu variabel $C$, maka proses selanjutnya adalah melakukan substitusi balik. Kode program untuk melakukan hal ini adalah

'subrutin untuk melakukan substitusi balik

Private Sub SubstitusiBalik()

Dim i, j As Integer

Dim s As Double

For $\mathrm{i}=2$ To 0 Step -1

$\mathrm{s}=\mathrm{H}(\mathrm{i})$

For $\mathrm{j}=\mathrm{i}+1$ To 2

$\mathrm{s}=\mathrm{s}-\operatorname{Data}(\mathrm{i}, \mathrm{j}) * \mathrm{X}(\mathrm{j})$

Next

$\mathrm{X}(\mathrm{i})=\mathrm{s} / \mathrm{Data}(\mathrm{i}, \mathrm{i})$

$$
\begin{aligned}
& \text { Next } \\
& A=X(0) \\
& B=X(1) \\
& C=X(2)
\end{aligned}
$$

End Sub

Dalam kode program di atas, variabel $A, B$, dan $C$ dihitung oleh persamaan $\mathrm{X}(\mathrm{i})$, di mana yang dihitung lebih dulu adalah $C$, kemudian $B$, dan terakhir $A$. Karena proses substitusi ini dimulai dari penentuan $C$ kemudian mundur sampai ke $A$, maka proses ini disebut substitusi balik. Setelah $A, B$, dan $C$ diketahui, maka program selanjutnya melakukan perhitungan laju alir optimum dan
$H$ minimum dengan hasil sebagaimana disajikan dalam Gambar 6.

\section{KESIMPULAN}

Berdasarkan uji program di atas maka dapat disimpulkan bahwa program yang dibuat dapat digunakan untuk menentukan tinggi plat teoritis dan laju alir optimum dari fasa gerak dalam kromatografi. Keuntungan menggunakan program ini dibandingkan menggunakan metode manual adalah perhitungan dapat dilakukan dengan lebih cepat dengan tingkat ketilitian tinggi dan tidak mengenal lelah.

\section{DAFTAR PUSTAKA}

Chapra, S. C. and R. P. Canale. 2006. Numerical Methods for Engineers. $5^{\text {th }}$ $E d$., McGraw-Hill, New York, NY 10020.

Conte, S. D. and Carl de Boer. 1980. Elementary Numerical Analysis. An Algorithmic Approach. $3^{\text {rd }} \quad E d$. McGraw-Hill, New York.

Dewobroto, W. 2004. Aplikasi Sain dan Teknik dengan Visual Basic 6.0. P.T. Elex Media Komputindo. Jakarta

Kennedy, J. H. 1990. Analytical Chemistry: Principles. Second Edition. Saunders College Publishing.

Munadi, S. 1995. Perhitungan Matriks dengan Quick Basic. Andi Offset. Yogyakarta.

Petroutsos, E., M. Ridgeway. 2008. Mastering Visual 2008, SYBEX Inc., 1151 Marina

Press, W. H., S. A. Teukolsky, W. T. Vetterling, B. P. Flannery. 2007. Numerical Recipes. The Art of Scientific Computing. $3^{\text {rd }}$ Ed., Cambridge University Press.

\section{Lampiran Kode Program}

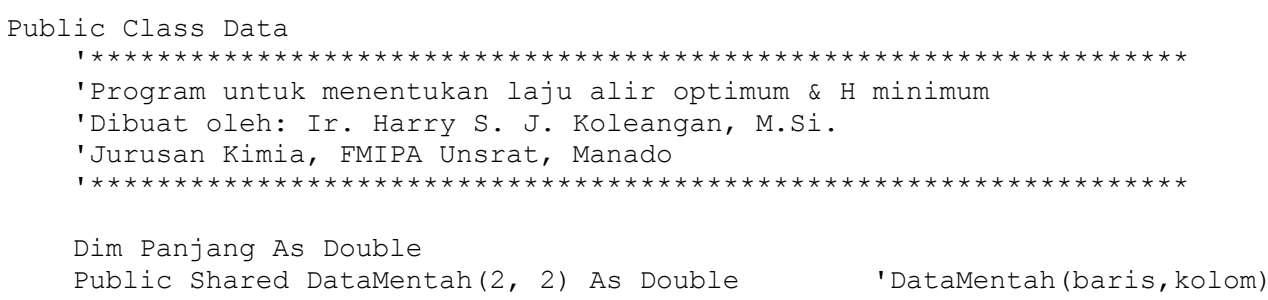


18 Jurnal Ilmiah Sains Vol. 12. No. 1, April 2012

Dim Data $(2,3), \mathrm{N}(2), \mathrm{H}(2), \mathrm{X}(2)$ As Double $\quad \mathrm{X}(0)=\mathrm{A}, \mathrm{X}(1)=\mathrm{B}, \mathrm{X}(2)=\mathrm{C}$

Public Shared A, B, C As Double

Dim LajuAliroptimumForm As New LajuAliroptimum

'subrutin untuk mengoreksi data (textbox) yang kosong

Private Sub Koreksi (ByVal Kotak As TextBox)

Kotak.Focus ()

Kotak.SelectAll ()

End Sub

'subrutin untuk memberikan komentar terhadap data kosong

Private Sub Komen(ByVal m As Integer, ByVal Keterangan As String)

MsgBox("Data " \& Keterangan \& " ulangan ke " \& $m+1$ \& " tidak diisi dengan benar", "Data Salah")

End Sub

'subrutin untuk memasukkan data

Private Sub MasukkanData()

Panjang $=\operatorname{CDbl}($ txtPanjang. Text)

'ulangan pertama

DataMentah $(0,0)=\operatorname{CDbl}($ txtLajuAlirl. Text)

DataMentah $(0,1)=\mathrm{CDbl}$ (txtWaktuRetensil.Text)

DataMentah $(0,2)=\operatorname{CDbl}$ (txtLebarPital. Text)

'ulangan kedua

DataMentah $(1,0)=\mathrm{CDbl}$ (txtLajuAlir2.Text)

DataMentah $(1,1)=\mathrm{CDb}$ (txtWaktuRetensi2.Text)

DataMentah $(1,2)=\operatorname{CDbl}$ (txtLebarPita2.Text)

'ulangan ketiga

DataMentah $(2,0)=\operatorname{CDbl}($ txtLajuAlir3. Text)

DataMentah $(2,1)=\operatorname{CDbl}($ txtWaktuRetensi3.Text)

DataMentah $(2,2)=\mathrm{CDbl}$ (txtLebarPita3.Text)

End Sub

'subrutin untuk validasi data

Private Sub ValidasiData()

Dim i, j As Integer

If Panjang $<=0$ Then

MsgBox("Data panjang kolom tidak diisi dengan benar", , "Data Salah")

Koreksi (txtPanjang)

Exit Sub

End If

For $i=0$ To 2

For $j=0$ To 2

If DataMentah $(i, j)<=0$ Then

If $j=0$ Then

Komen (i, "Laju Alir")

If $i=0$ Then

Koreksi (txtLajuAlir1)

Exit Sub

End If

If $i=1$ Then

Koreksi (txtLajuAlir2)

Exit Sub

End If

If $i=2$ Then

Koreksi (txtLajuAlir3)

Exit Sub

End If

End If

If $j=1$ Then

Komen ( $i+1$, "Waktu Retensi")

If $i=0$ Then

Koreksi (txtWaktuRetensi1) Exit Sub

End If

If $i=1$ Then

Koreksi (txtWaktuRetensi2)

Exit Sub

End If

If $i=2$ Then

Koreksi (txtWaktuRetensi3) Exit Sub

End If

End If

If $j=2$ Then

Komen $(i+1$, "Lebar Pita")

If $i=0$ Then 


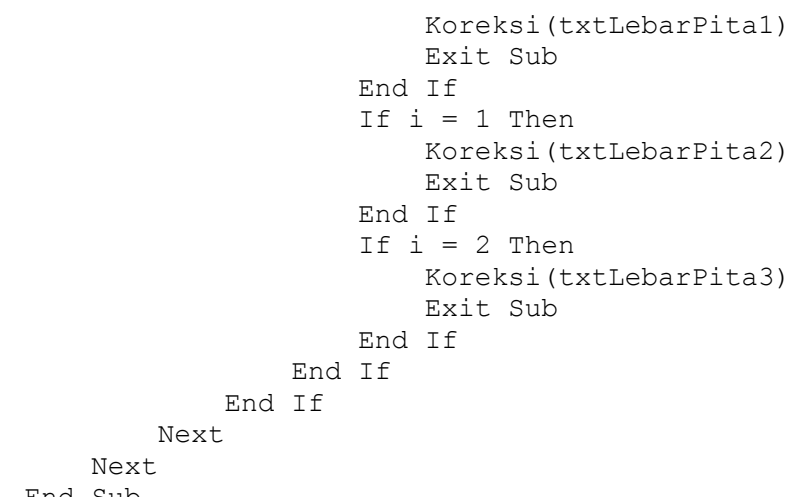

End Sub

'subrutin untuk menghitung koefisien dari A, B, C dan nilai N dan H dalam pers VD Private Sub KoefABC(

Dim i, j As Integer 'i=banyaknya baris, j=banyaknya kolom

For $i=0$ To 2

$N(i)=(4 *$ DataMentah $(i, 1) /$ DataMentah $(i, 2)) \wedge 2$

$\mathrm{H}(\mathrm{i})=$ Panjang $/ \mathrm{N}(\mathrm{i})$

For $j=0$ To 3

Select Case

Case 0 $\operatorname{Data}(i, j)=1$

Case 1

$\operatorname{Data}(i, j)=1 / \operatorname{DataMentah}(i, 0)$

Case 2

$\operatorname{Data}(i, j)=\operatorname{DataMentah}(i, 0)$

Case 3

End Select

Next

Next

End Sub

'subrutin untuk melakukan eliminasi

Private Sub Eliminasi()

Dim i, j, $k$ As Integer

Dim Pengali As Double

For $i=0$ To 2

For $k=i+1$ To 2

Pengali $=\operatorname{Data}(k, i) / \operatorname{Data}(i, i)$

For $j=i+1$ To 2

Next

$\operatorname{Data}(k, j)=\operatorname{Data}(k, j)-\operatorname{Pengali}$ * $\operatorname{Data}(i, j)$

$\mathrm{H}(\mathrm{k})=\mathrm{H}(\mathrm{k})-$ Pengali * $\mathrm{H}(\mathrm{i})$

$\operatorname{Data}(k, i)=0$

Next

Next

End Sub

'subrutin untuk melakukan substitusi balik

Private Sub SubstitusiBalik()

Dim i, j As Integer

Dim $s$ As Double

For $i=2$ To 0 Step -1

$\mathrm{s}=\mathrm{H}(\mathrm{i})$

For $j=i+1$ To 2

$s=s-\operatorname{Data}(i, j) \star x(j)$

Next

Next

$\mathrm{X}(\mathrm{i})=\mathrm{s} / \operatorname{Data}(\mathrm{i}, \mathrm{i})$

$\mathrm{A}=\mathrm{X}(0)$

$\mathrm{B}=\mathrm{X}(1)$

$C=X(2)$

End Sub

Private Sub btExit_Click(ByVal sender As System.Object, ByVal e As System.EventArgs) Handles btExit.Click

Me.Close ()

End Sub

'subrutin untuk menghitung laju alir optimum dan $\mathrm{H}$ minimum

Dim lajuoptimum As Double 
20 Jurnal Ilmiah Sains Vol. 12. No. 1, April 2012

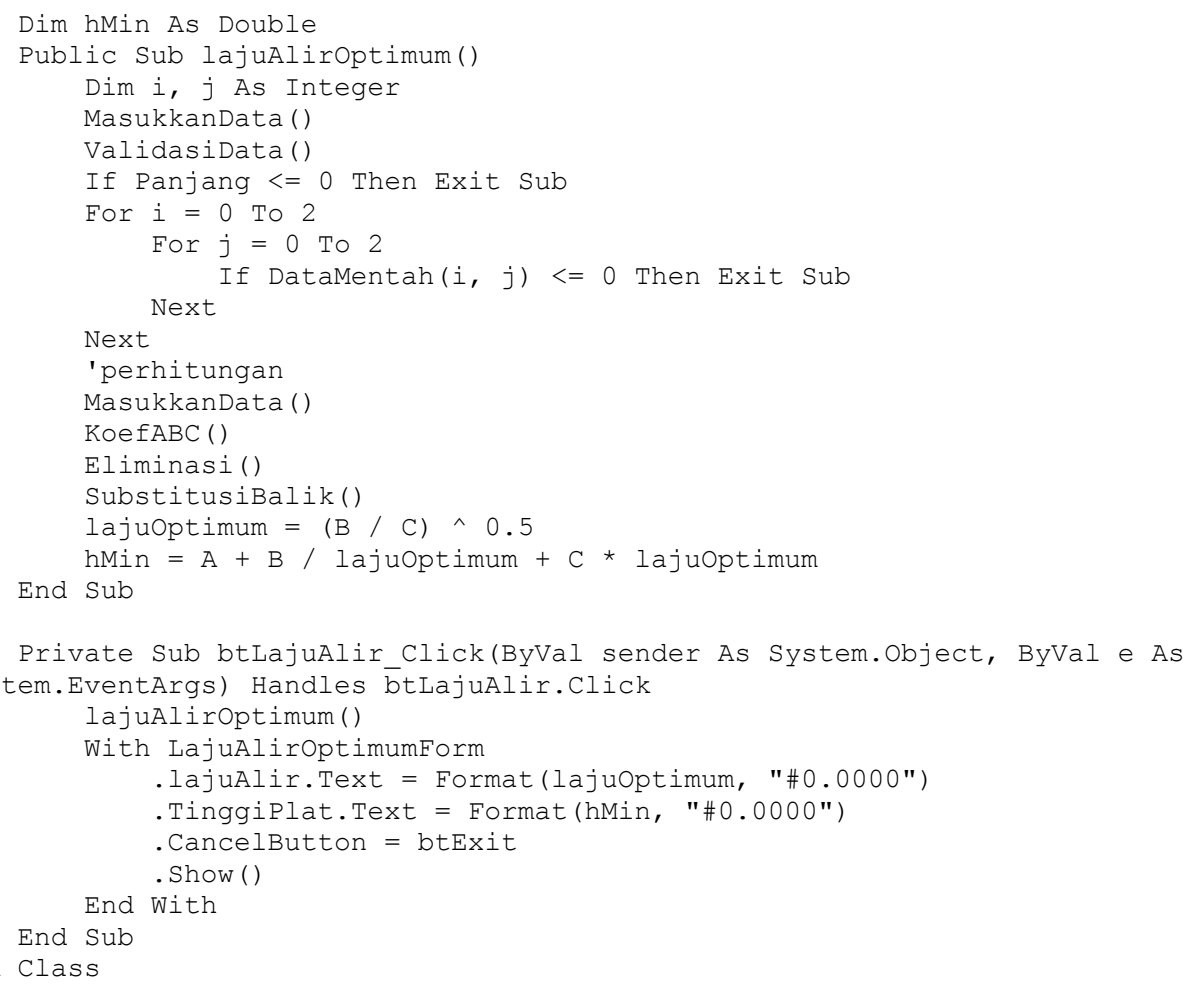

